\title{
EXPERIENCES WITH REMOTE TEACHING OF MANUFACTURING ENGINEERING LABORATORY AND PROJECT COURSES
}

\author{
Casey Keulen* and Christoph Sielmann \\ Faculty of Applied Sciences, The University of British Columbia \\ *Corresponding Author: casey.keulen@ubc.ca
}

\begin{abstract}
COVID-19 has profoundly affected many, if not all, Canadian engineering courses during the 2020/2021 academic year, many of which transitioned to online teaching. Delivering hands-on, highly interactive laboratory and design project courses is particularly challenging to do remotely.

We present and reflect on experiences with remote teaching of three hands-on laboratory courses in a new Manufacturing Engineering program at the University of British Columbia (UBC). These courses include MANU 230: Manufacturing Laboratory, MANU 330: Manufacturing Engineering Project I, and MANU 386: Industrial Automation. All three courses are taught in the same laboratory/classroom by one of the authors.

In general, it appears that the students appreciated the remote lab experiences provided. However, it was apparent from both survey data and informal feedback that students preferred in-person laboratory sessions. While, perhaps not an ideal method of delivering these types of courses there appears to be some place for remote laboratory classes in the future.
\end{abstract}

Keywords: Remote Lab Course, Online Lab, Remote Design Course, Remote Hands-on, Manufacturing Engineering, Remote Teaching

\section{INTRODUCTION}

COVID-19 has profoundly affected many, if not all, Canadian engineering courses during the 2020/2021 academic year; many of which transitioned to online teaching. Delivering hands-on, highly interactive laboratory and design project courses is a particularly challenging task. These types of hands-on courses provide a practical, 'real world' perspective that compliments theory-driven engineering courses. The challenge for instructors is replicating these experiences and lessons in decentralized and remote environments that lack physical instructional support.

Delivering quality laboratory education remotely is explored by others such as Daniel, who considers that "There is a high probability of graduating some of the COVID-19 cohort of students without adequate laboratory skills and practice; they may be at a long-term disadvantage, compared to those who studied 'normally,' when they move to another level of study or enter the labor market." [1]

It is estimated that over 1.7 billion students have had their education disrupted by the pandemic [2]. From this statistic we can infer that educators from around the world are moving hands-on courses online. One interesting initiative to establish best practices of online lab courses originated at the University of Oxford. It is referred to as \#Drylabs20 and is a recently established network of over 100 delegates in the U.K., mainland Europe, North America, and Australasia that considers how practical chemistry can be taught online/remotely [3]. This network has acted as a catalyst for the creation of similar spin-off groups such as DryLabsRealScience (Biology), PHYSICSLTHE (Physics), DryLabsDownUnder (Australasian Chemistry group). These networks aim to generate and share methodologies, pedagogies, and best practices for administering laboratory courses remotely.

Remote lab courses for science and engineering are not entirely new; Taft describes teaching exclusively online for more than five years [4], while Gamage refers to online lab courses that were taught in the first decade of the $21^{\text {st }}$ century [5].

There appears to be some effort made to provide open source lab course content in science and engineering by groups around the world. An example is ECUST in Shanghai, that boasts approximately 160 experiments suitable for remote delivery as 'simulations', 'virtual experiments', or 'remote control experiments' on topics such as chemistry, physics, chemical engineering, machine principles, controls, computer networking, electrical machines, electrical circuits, transducers, materials engineering, basic mechanical engineering, computer graphics, and monitoring technologies [5], [6].

In addition to academic resources, there are commercial enterprises with a mandate to support online laboratory courses. These companies have lab lessons hosted online with premade kits that can be ordered and sent directly to students. Others will assemble a custom lab kit. [4]

These resources benefit many educational programs and sectors, however, a comprehensive examination of available remote labs show few resources appropriate for manufacturing engineering laboratory courses. 


\subsection{Remote Labs in Manufacturing Engineering}

When MANU 230, MANU 330, and MANU 386 were being adapted for remote delivery, methods suitable for manufacturing engineering were considered, including: simulation based, instructor led live demonstrations, remote connection to equipment, and take-home activities. Postponing the lab course entirely until students were back on campus was another option in lieu of remote delivery.

Simulation based lab demos use simulation software, typically finite element analysis (FEA), to demonstrate the manufacturing process in question. The software is used by students asynchronously to complete the lab activities. Benefits include the ability for students to adjust the input parameters and develop an understanding of their effect on the process. The disadvantages include a significant learning curve for the software (often a new package is required for each process) as well as a cost to provision the software for student use when students are distributed across the world and subject to different export control laws.

Live demonstrations closely resemble the activities the students would have done in person. They are performed by an instructor or Teaching Assistant (TA). The session is recorded and posted on the course learning management system (LMS) for asynchronous viewing. The benefits of this approach include exposure to the same material, equipment and activities that they would experience inperson. There is also the opportunity to ask the instructor questions mid-activity that may be otherwise constrained in an in-person format. A significant disadvantage is the lack of physical presence in the lab for first-hand experience applying the process and operating the equipment.

There is the possibility of remotely connecting to equipment for some lab activities. Some equipment allows remote access and control whereby students can operate the equipment in real time. Remote access closely resembles what students would experience in industry as the prevalence of remotely controlled processes/automation continues to grow. Although a good approach, it is limited by the availability of suitable equipment.

Take-home activities require that instructors send students a package of items that would be used at home to complete the lab activities. Having equipment at home provides the student some hands-on experience, however logistics and expense limit the scope of what can be sent home. For example, it would not be practical to send every student a CNC milling machine.

A further option adopted by some is to postpone the lab courses until students are back on campus. Although an attractive option for instructors as it reduces the need to adjust the course lab experience, it inevitably postpones the graduation date of many students and could become problematic if in-person instruction is delayed for more than a year. It is also not clear if the students would prefer to postpone lab courses or do them remotely. Dietrich et al. did a survey and received a near uniform distribution across 'Strongly disagree', 'Disagree', 'Neither agree nor disagree', 'Agree', 'Strongly agree' that cancelling lab course work was a good option [2]. As of this writing, students have not been on campus for nearly one calendar year, with uncertainty as to when they will return. Postponing courses requires make-up courses which can conflict with established program schedules and other required courses.

\subsection{Assessment Methodology}

Course instructors were given the opportunity to choose how to facilitate remote delivery of labs in their courses for the 2020/2021 academic year. The MANU program chose three remote lab delivery options for three $2^{\text {nd }}$ and $3^{\text {rd }}$ courses. The following presents and reflects on experiences with remote teaching of three hands-on laboratory courses in the new Manufacturing Engineering program at a Canadian HEI. These courses are either taught for the first or second time and include MANU 230: Manufacturing Laboratory, MANU 330: Manufacturing Engineering Project I, and MANU 386: Industrial Automation. All three courses are taught in the same laboratory/classroom. Students in the 300 level courses are familiar with the lab space because they all took MANU 230 in that space the previous year. Students in the 200-level course are not familiar with the lab space. Each course has different requirements for student participation, engagement, and interaction, leveraging a variety of pedagogical approaches.

Student feedback through informal interactions and a survey as part of continuous improvement was collected. In general, the results showed an overall positive sentiment among students undertaking remote labs in the program. These results will be discussed in more detail below.

\section{COURSE DESCRIPTIONS}

\subsection{MANU 230 - Manufacturing Laboratory}

MANU 230 - Manufacturing Laboratory is the first course in The University of British Columbia MANU curriculum that is focused entirely on manufacturing. It is a two term, four credit course. It covers manufacturing processes for metals (turning, milling, abrasive cutting, casting, rolling, forming, and heat treating), polymers (injection moulding, thermoforming, and 3D printing), and composites (wet layup, vacuum infusion, and prepreg layup).

The course takes a more didactic approach, where students are led through the activities remotely by the instructor, then continue their lessons and assignments on their own with items supplied in a 'Lab-in-a-box' kit.

It was decided to emulate the in-lab experience as much as possible by having the instructor do live laboratory 
sessions through Zoom, allowing students to see equipment and processes in action, improving their understanding of how they function, and providing benefits from the experience of observing each process from start to finish. Students asked questions during the session and the instructor provided ad hoc demonstrations, lessons, or explanations. A synchronous, interactive lab experience was a necessary part of the lab.

The activities demonstrated in the lab session were consistent with the in-person version of the lab. Sessions were recorded and posted to the LMS for students unable to join live (often due to being in other time zones) or others interested in reviewing content after the scheduled lab class.

To facilitate these sessions a computer monitor stand with wheels and a flexible webcam mount was setup as shown in Figure 1. This mobile camera platform allowed the instructor to use their laptop with a second monitor, which helped when presenting slides or when multiple windows were required. A webcam on a flexible mount was used to record the demonstrations. The flexible mount allowed the camera to be positioned in a number of positions quickly. A quick release mechanism on the mount allowed the webcam to be removed and hand held for even more options (mostly used for close ups). While performing the demonstrations the instructor was wearing a wireless lavalier (lapel) microphone to permit the instructor to move freely in the lab.

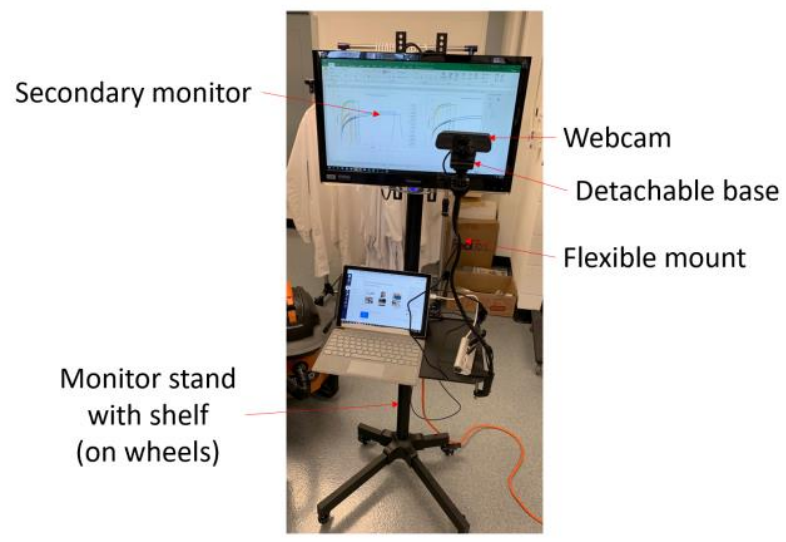

Figure 1: Mobile computer setup for remote teaching in lab setting.

In previous years the class toured a research lab that was particularly relevant to one of the modules. This year a walkthrough video tour of that lab was recorded that had minimal discussion/explanation from the tour host. During the lab session, the video was played and narrated in realtime by the instructor. Providing a pre-recorded lab tour enabled easy pausing of the tour to go into more detail about the equipment. Since it was being hosted via Zoom, the instructor easily shared images and schematics while contributing additional notes and diagrams to the images. To give an example of how much time was used to explain/discuss the images in the video, the running time of the lab tour video was $\sim 15$ minutes, but the virtual tour lab session lasted for $\sim 110$ minutes.

The live demonstrations were a suitable method of exposing students to processes and equipment, however they lacked the physical, hands-on aspect. To address this, students were supplied with a kit of items (fondly referred to as a "Lab-in-a-box") to help enhance each student's learning experience during the online laboratory demonstrations. Kit contents are shown in Figure 2. Many of the items manufactured and/or discussed in the live sessions were included in the kit. Students were able to inspect and examine parts while they were watching similar parts being manufactured during the lab session. For example, they were provided with a sample part turned on a lathe. When the instructor discussed 'chatter' and its effect on lathe fabricated parts, the students could examine the part provided to them in the kit and observe these effects. The rough cost of the Lab-in-a-box kit was $\sim$ \$150/student after shipping (a mix of local, domestic, and international shipping), excluding labor. The cost to run these labs in person is significantly less, $\sim \$ 25 /$ student since students work in groups and shipping is not necessary.

Students would use items in these kits to complete their assignments. For example, they would use the provided digital calipers to measure the thickness of a composite panel and, based on information provided in the constituent material's technical data sheet, coupled with specific lab processes, the student calculated the fibre volume fraction. Other activities included examining a cast aluminum part, a 3D printed part, thermoformed plastic parts, and injection moulded parts. Tools were provided to allow students to tap the surface of an aluminum plate and inspect it with a magnifying glass afterward. The results of tensile specimens were included to demonstrate the difference between a plastic and brittle failure.

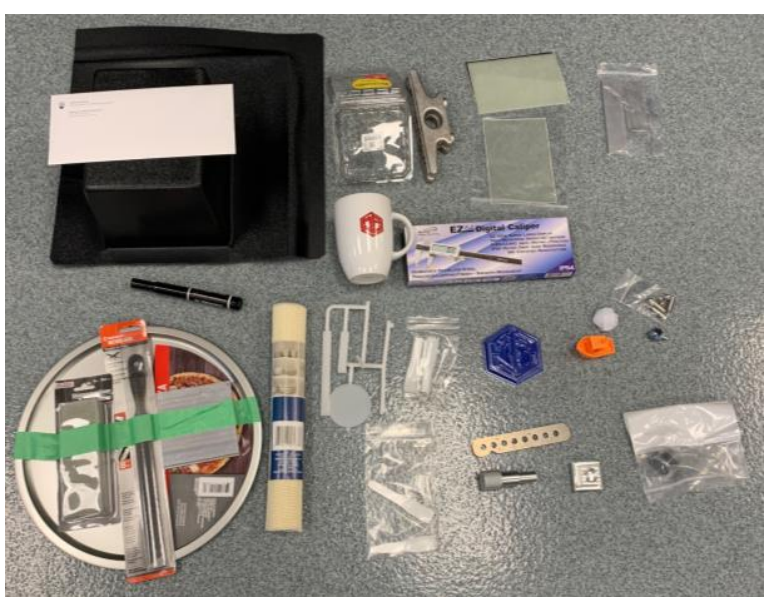

Figure 2: Example of contents of Lab-In-A-Box 


\subsection{MANU 330 - Manufacturing Engineering Project I}

MANU 330 - Manufacturing Engineering Project I is a two term, six credit course intended to introduce students to the design of manufacturing processes. The course is divided into four sub-projects, each yielding components that come together to produce one assembly. The first subproject focuses on high level design of the three major components, while the next three sub-projects focus on designing the part and manufacturing process for a particular component, with the ultimate goal of producing part(s) and delivering a report on the manufacturing process. Each group of four or five students created their own assembly and participated in a competition at the end of the term.

MANU 330 is taught using a more learner-centered modality than MANU 230, where the students use their lab time to guide the instructor/teaching assistants to build their design project. Students are encouraged to think of this approach as more representative of working in industry, where engineers often provide technical guidance to equipment operators and technicians rather than operating the equipment themselves.

Students in this course completed MANU 230 in person and are familiar with the equipment and manufacturing processes available to them in the laboratory.

The same monitor stand described earlier and shown in Figure 1 was used during the lab time. Most of the lab time consisted of private group time so individual groups had a chance to perform experiments and/or trial fabrication processes 'one-on-one' with the instructor. The objective was for students to collect enough information to perform their analyses and complete the report on a particular manufacturing process.

\subsection{MANU 386 - Industrial Automation}

MANU 386 - Industrial Automation introduces students in the MANU program to principles of industrial automation, including PLC and SCADA driven control systems, industrial communications, sensors, actuators, robotics, and emerging technologies grounded in Industry 4.0. A common theme in industrial automation is remote access, where engineers, operators, and technicians control manufacturing processes remotely using a variety of communication technologies. This common industry practice served as inspiration for remote labs facilitated through MANU 386.

Students are tasked to automate a manufacturing process with no physical access to the lab space. This lab approach prioritizes distributed teamwork, mimicking decentralized automation design and implementation found in many modern industrial facilities. Some students will engage directly with automation programming while others concurrently perform related tasks such as controls tuning and user interface design with the objective to complete their own, remotely controlled, fully automated process without physically touching any of the devices that comprise the lab. Remotely accessible cameras and robotic arms compliment the student remote learning experience.

Cybersecurity is a prominent concern when implementing any remote access technology, and extensive work was required with university IT to formulate an appropriate approach, with the outcome documented in Figure 3. Laptops were situated in the lab space, pointed at the automation kits. The laptops were connected to the university intranet and were configured for remote student access through conventional Remote Desktop Protocol (RDP).

The automation kits, consisting of ClickPLC series programmable logic controllers, and Kinova series robots were isolated into a separate NAT addressable network for added security through restricted access to users of the university network. A GL.iNet GL-AR750 gateway was used to bridge the Automation intranet and university network. To facilitate remote access, OpenVPN was configured on the gateway with clients installed on lab laptops. The access certificate is changed every semester to ensure that only current students have access to the network.

\section{LAB NETWORK DRAWING}

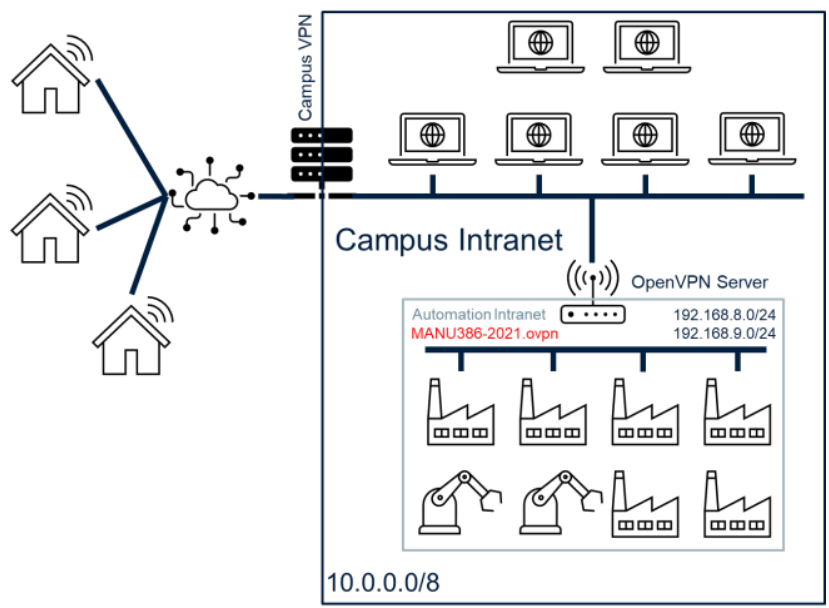

Figure 3: Automation Intranet Connection Diagram

To provide as much flexibility as possible, students should be able to access the automation equipment remotely. Achieving this first requires connecting to the university VPN, based on Cisco AnyConnect. A further OpenVPN connection is also required to connect to the automation intranet, though this is not possible with AnyConnect active. To circumvent this problem, a Linuxbased virtual machine (VM) was provided to students that would form the OpenVPN connection through the university VPN and allow VM access to the automation intranet. Between laptop RDP, university VPN, and OpenVPN, students were able to communicate securely with all required lab technologies from anywhere in the 
world, with the automation intranet requiring at least two levels of authentication.

The automation kits and robots engaged in motion when programmed by the students, meaning that a means for students to see their lab kits remotely was required. Realtime camera imagery was provided cost effectively by pointing the lab laptops at the automation kits, as shown as in Figure 4. Students were able to engage in group work by collaborating in real-time using Zoom or Microsoft Teams and sharing desktops to show imagery of the lab kits, PLC code, SCADA projects, and other relevant lab content.

This fully remote automation lab experience simulates a fairly common practice in industrial automation projects today where one or more team members participate in the programming and commissioning of the site entirely through remote access technologies.

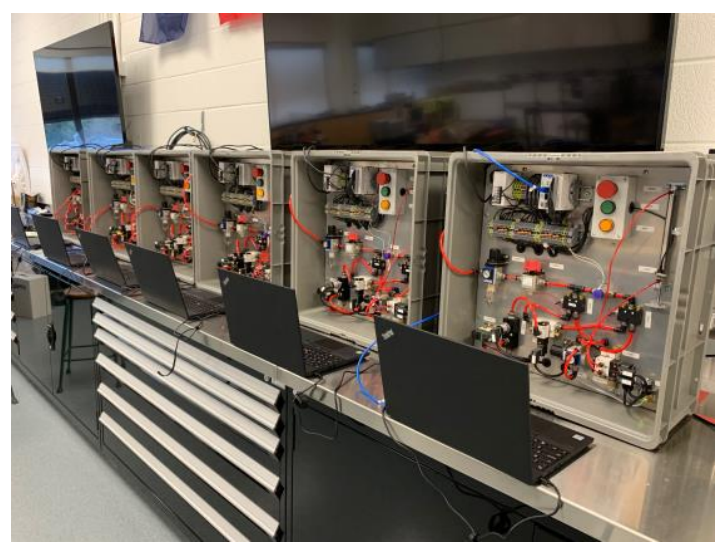

Figure 4: Lab automation kits and laptops.

\section{DISCUSSION AND CONCLUSION}

An anonymous online survey was sent out to students to gauge their perception of the course and receive feedback. One survey was sent to the students in MANU 230 and a separate survey was sent to the students in MANU 330 and MANU 386 (the same students were in both 300 level courses). Both surveys shared eight common questions (Q1-8 shown in Table 1Table 3). The survey for MANU 230 students included five questions specific to MANU 230 (Q9-13 in Table 1), while the other survey included five and four questions specific to MANU 330 (Q9-13 in Table 2) and MANU 386 (Q9-Q12 in Table 3), respectively. The response rate was $11 / 18$ and $23 / 48$ for MANU 230 and MANU 330/386, respectively.

The survey questions are listed in Table 1-Table 3, with the results presented in Figure 5-Figure 7. A Likert scale of 1-5 with $1=$ Strongly disagree, $2=$ Somewhat disagree, 3 $=$ Neither agree nor disagree, $4=$ Somewhat agree, $5=$ Strongly agree was used for each question. The error bars in Figure 5-Figure 7 indicate the standard deviation. The questions were designed such that higher scores were more favorable to online laboratory classes.
Table 1: Questions asked of MANU 230 students

\begin{tabular}{ll}
\hline Q1 & $\begin{array}{l}\text { The lab session delivery method was effective (ie. live } \\
\text { Zoom sessions). }\end{array}$ \\
\hline Q2 & $\begin{array}{l}\text { I feel that I have developed a good understanding of the } \\
\text { material that was taught in the course. }\end{array}$ \\
\hline Q3 & $\begin{array}{l}\text { I felt an appropriate amount of time was spent on each } \\
\text { module/topic. }\end{array}$ \\
\hline Q4 & $\begin{array}{l}\text { The method of instruction and assessment was different but } \\
\text { equal to what I expected from an in-person experience. }\end{array}$ \\
\hline Q5 & $\begin{array}{l}\text { I felt that we were able to ask more questions and engage in } \\
\text { discussions more easily online compared to in-person. }\end{array}$ \\
\hline Q6 & $\begin{array}{l}\text { I think there is a place for online lab courses in the future. } \\
\text { Q7 }\end{array}$ \\
\hline Q8 & $\begin{array}{l}\text { I would have preferred to have postponed this course until } \\
\text { we were back on campus. } \\
\text { taking this course. }\end{array}$ \\
\hline Q9 & $\begin{array}{l}\text { The Lab-in-a-box kit provided a good connection to what } \\
\text { was taught/demonstrated in class. }\end{array}$ \\
\hline Q10 & $\begin{array}{l}\text { The Lab-in-a-box kit helped provide some hands-on } \\
\text { connection to the course content. }\end{array}$ \\
\hline Q11 & $\begin{array}{l}\text { I would have appreciated more group work in the lab } \\
\text { sessions. }\end{array}$ \\
\hline Q12 & $\begin{array}{l}\text { A good connection was made between the material } \\
\text { presented in the lectures and the lab sessions. }\end{array}$ \\
\hline Q13 & $\begin{array}{l}\text { The video tour of the Composites Research Network was } \\
\text { more informative because we were able to ask questions, } \\
\text { stop the video and discuss various topics with the aid of } \\
\text { sketches and images. }\end{array}$ \\
\hline
\end{tabular}

In general, the students responded positively. The highest response was 4.7 for Q3 and Q12 of the MANU 230 survey and Q10 of the MANU 386 survey. The lowest response was 2.7 for Q6 of the MANU 230 survey. The trends were quite similar for students in MANU 230, MANU 330, and MANU 386 for the questions that were common to all students (Q1-8).

MANU 230 students responded with the highest average results. The highest score of 4.7 was from Q3: 'I felt an appropriate amount of time was spent on each module/topic.', and Q12: 'A good connection was made between the material presented in the lectures and the lab sessions.'. These are both related more to the course content and not necessarily related to remote teaching. The second highest responses from MANU 230 students were from Q9 and Q10, of 4.6. These both related to the Lab-ina-box kit, suggesting that students appreciated this.

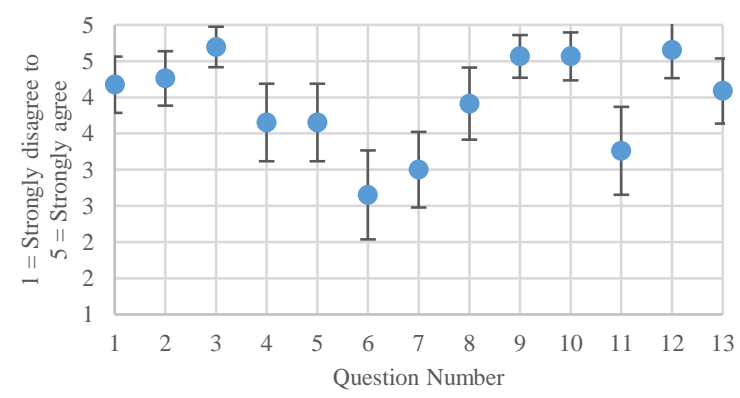

Figure 5: Response of MANU 230 students to the survey questions in Table 1 
The lowest scores from MANU 230 students were from Q6, Q7, and Q11. The response to Q6: 'I think there is a place for online lab courses in the future.', of 2.7 suggests that while the students did not see remote laboratory courses as an ideal replacement for in-class labs they did see it as having potential in some situations. The response to Q7: 'I would have preferred to have postponed this course until we were back on campus.', of 3.0 suggests that that students were ambivalent to postponing the course until they were back on campus, suggesting that while students may have preferred to do the sessions live, they felt that they were beneficial enough to not postpone them and suffer the consequences of making up courses and/or postponing their graduation date. The response to Q11 of 3.3 suggests that the students were ambivalent to the group work common to lab courses.

\section{Table 2: Questions asked of MANU 330 students}

\begin{tabular}{|c|c|}
\hline Q1 & $\begin{array}{l}\text { The lab session delivery method was effective (ie. live } \\
\text { Zoom sessions). }\end{array}$ \\
\hline Q2 & $\begin{array}{l}\text { I feel that I have developed a good understanding of the } \\
\text { material that was taught in the course. }\end{array}$ \\
\hline Q3 & $\begin{array}{l}\text { I felt an appropriate amount of time was spent on each } \\
\text { module/topic. }\end{array}$ \\
\hline Q4 & $\begin{array}{l}\text { The method of instruction and assessment was different } \\
\text { but equal to what I expected from an in-person } \\
\text { experience. }\end{array}$ \\
\hline Q5 & $\begin{array}{l}\text { I felt that we were able to ask more questions and } \\
\text { engage in discussions more easily online compared to } \\
\text { in-person. }\end{array}$ \\
\hline Q6 & $\begin{array}{l}\text { I think there is a place for online lab courses in the } \\
\text { future. }\end{array}$ \\
\hline Q7 & $\begin{array}{l}\text { I would have preferred to have postponed this course } \\
\text { until we were back on campus. }\end{array}$ \\
\hline Q8 & $\begin{array}{l}\text { I am more comfortable doing online lab sessions after } \\
\text { taking this course. }\end{array}$ \\
\hline Q9 & $\begin{array}{l}\text { Group activities were easy to plan and execute in an } \\
\text { online environment. }\end{array}$ \\
\hline Q10 & $\begin{array}{l}\text { Having the instructor perform activities in the lab } \\
\text { according to our direction was a good way to experience } \\
\text { and learn more about the process. }\end{array}$ \\
\hline Q11 & $\begin{array}{l}\text { By doing these projects I was able to gain more insight } \\
\text { and develop a better understanding of the processes } \\
\text { covered. }\end{array}$ \\
\hline Q12 & $\begin{array}{l}\text { A good connection was made between the material } \\
\text { presented in the lectures and what was asked for in the } \\
\text { reports. }\end{array}$ \\
\hline Q13 & $\begin{array}{l}\text { Being familiar with the laboratory facilities in person } \\
\text { was beneficial to this course. }\end{array}$ \\
\hline
\end{tabular}

The lowest rated question in the MANU 330 specific survey was Question \#9: 'Group activities were easy to plan and execute in an online environment.', with a value of 3.3. This suggests that students found group work challenging and/or less enjoyable. It is not clear if this is related to remote learning or is fundamental to the design of the lab, or group work in general. The next lowest response was to Q10: 'Having the instructor perform activities in the lab according to our direction was a good way to experience and learn more about the process.', with a value of 3.3. This suggests that students did not necessarily feel that observing the instructor perform the activities helped them understand the process better. Since getting a better understanding of the process is an important part of the course, an alternative approach could be employed if/when this course is held remotely in the future. The highest response was to Q13: 'Being familiar with the laboratory facilities in person was beneficial to this course.', with a value of 4.5. This suggests that having experience in the laboratory facilities used to administer the course was appreciated by students and potentially benefitted them. More investigation into the learning outcomes of students taking remote lab courses that are familiar with the facilities vs students that are not may be worthwhile.

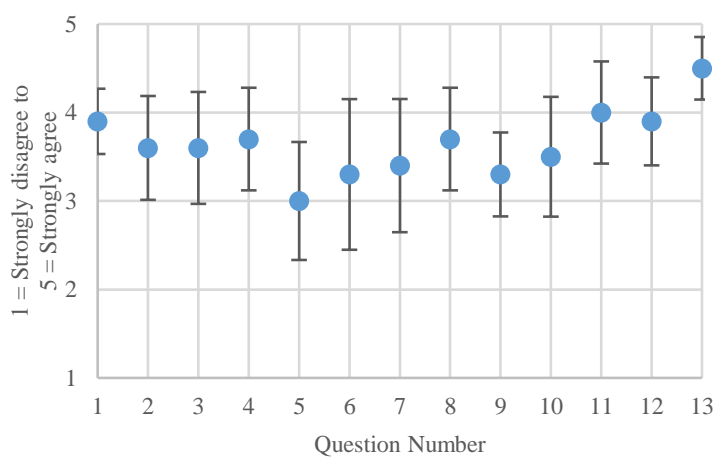

Figure 6: Response of MANU 330 students to the survey questions in Table 2

The results of MANU 386 show that students enjoyed remotely accessing the lab equipment and found it relevant to their professional goals. The highest response was to Q10: 'Remotely controlling automation equipment is relevant to my professional goals.', of 4.6. This suggests that students in the program are both interested in remote access automation as a career path and that this is one aspect of MANU 386 that should be considered to retain when the course is taught in person. The two lowest scores came from Q11: 'I preferred to conduct labs using remote desktop protocol (RDP) and software on the lab laptop vs. connecting directly to the automation system using software on my home computer.' and Q12: 'Using group member roles within each lab promoted my understanding of different roles engineers carry in industry.', of 3.1. This suggests that students were ambivalent to how they remotely connected to the lab equipment and the use of group member roles.

In general, it appears that the students in the examined cohorts appreciated the remote lab experiences provided. However, it was apparent from both informal feedback (in/out of class discussions) and the comparatively low response to Q6: 'I think that there is a place for online lab courses in the future' that the students preferred in-person laboratory sessions with the possible exception of the remote access work in MANU 386, which the students 
responded positively to. While, perhaps not an ideal method of delivering these types of courses there appears to some place for remote laboratory classes in the future.

Table 3: Questions asked of MANU 386 students

\begin{tabular}{|c|c|}
\hline Q1 & $\begin{array}{l}\text { The lab session delivery method was effective (ie. live } \\
\text { Zoom sessions). }\end{array}$ \\
\hline Q2 & $\begin{array}{l}\text { I feel that I have developed a good understanding of the } \\
\text { material that was taught in the course. }\end{array}$ \\
\hline Q3 & $\begin{array}{l}\text { I felt an appropriate amount of time was spent on each } \\
\text { module/topic. }\end{array}$ \\
\hline Q4 & $\begin{array}{l}\text { The method of instruction and assessment was different } \\
\text { but equal to what I expected from an in-person } \\
\text { experience. }\end{array}$ \\
\hline Q5 & $\begin{array}{l}\text { I felt that we were able to ask more questions and engage } \\
\text { in discussions more easily online compared to in-person. }\end{array}$ \\
\hline Q6 & $\begin{array}{l}\text { I think there is a place for online lab courses in the } \\
\text { future. }\end{array}$ \\
\hline Q7 & $\begin{array}{l}\text { I would have preferred to have postponed this course } \\
\text { until we were back on campus. }\end{array}$ \\
\hline Q8 & $\begin{array}{l}\text { I am more comfortable doing online lab sessions after } \\
\text { taking this course. }\end{array}$ \\
\hline Q9 & $\begin{array}{l}\text { Remotely accessing real lab equipment improved my } \\
\text { confidence in my understanding of the course material. }\end{array}$ \\
\hline Q10 & $\begin{array}{l}\text { Remotely controlling automation equipment is relevant } \\
\text { to my professional goals. }\end{array}$ \\
\hline Q11 & $\begin{array}{l}\text { I preferred to conduct labs using remote desktop protocol } \\
\text { (RDP) and software on the lab laptop vs. connecting } \\
\text { directly to the automation system using software on my } \\
\text { home computer. }\end{array}$ \\
\hline Q12 & $\begin{array}{l}\text { Using group member roles within each lab promoted my } \\
\text { understanding of different roles engineers carry in } \\
\text { industry. }\end{array}$ \\
\hline
\end{tabular}

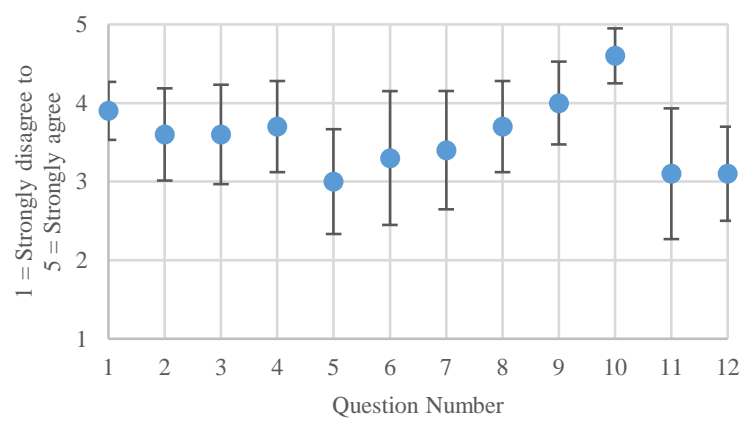

Figure 7:Response of MANU 386 specific questions in Table 3

\section{Acknowledgements}

We would like to thank the students who completed the survey. The primary focus of this work is quality assurance and improvement within a specific program. TCPS2 ethical guidelines were followed in engaging student participation, maintaining anonymity in data collection and storage, minimizing risk to vulnerable students, and promoting beneficence. This work will be applied directly and immediately to improving the course and program.

\section{References}

[1] J. Daniel, "Education and the COVID-19 pandemic," Prospects, vol. 49, no. 1, pp. 91-96, 2020.

[2] N. Dietrich et al., "Attempts, successes, and failures of distance learning in the time of COVID-19," J. Chem. Educ., vol. 97, no. 9, pp. 2448-2457, 2020.

[3] C. D. Campbell, B. Challen, K. L. Turner, and M. I. Stewart, "\# DryLabs20: A New Global Collaborative Network to Consider and Address the Challenges of Laboratory Teaching with the Challenges of COVID-19," J. Chem. Educ., vol. 97, no. 9, pp. 3023-3027, 2020.

[4] H. Taft, "How to Quickly (and Safely) Move a Lab Course Online," CHE, Mar. 17, 2020 https://www.chronicle.com/article/how-to-quickly-andsafely-move-a-lab-course-online/ (accessed Feb. 16, 2021).

[5] K. A. Gamage, D. I. Wijesuriya, S. Y. Ekanayake, A. E. Rennie, C. G. Lambert, and N. Gunawardhana, "Online delivery of teaching and laboratory practices: Continuity of university programmes during COVID-19 pandemic," Educ. Sci., vol. 10, no. 10, p. 291, 2020.

[6] M. Endean and N. Braithwaite, Online Practical Work for Science and Engineering Students-A Collaborative Scoping Activity between the UK Open University and East China University of Science and Technology. 